\title{
Effects of Crushed RAP on Free and Restrained Shrinkage of Mortars
}

\author{
Ilker Bekir Topcu' ${ }^{1)}$ and Burak Isikdag ${ }^{2)}$
}

(Received April 15, 2009, Revised November 17, 2009, Accepted November 20, 2009)

\begin{abstract}
Reclaimed asphalt pavement (RAP) is abundant substitute for natural aggregate in many areas. It is obtained by crushing of old road pavements in milling machine during rehabilitation and reconstruction process. In this study, reclaimed asphalt pavement mortars (RAPM) have been produced with different cement dosages and replacement ratios. The destructive and nondestructive tests have been conducted on specimens to determine physical and mechanical properties of RAPM. The free and restrained shrinkage tests on RAPM have been conducted to predict fractural behavior of mortars. The aim of the shrinkage tests was to delay crack formation and improve strain capacity of mortars before cracking. The results showed that RAPM exhibits lower elasticity modulus; however the tensile capacity was improved for deformation before cracking.
\end{abstract}

Keywords : recycling, mechanical property, mortar, cracking, shrinkage.

\section{Introduction}

The use of recycled materials in cement based composites has become more popular in recent years. Each year, 73 million tons of reclaimed asphalt pavements (RAP) have been reused. RAP is used not only for new roads, but also for roadbeds, shoulders and embankments. The U.S. highway industry generates over 100 million tons of RAP through the rehabilitation and reconstruction of existing highways. Asphalt pavements (roads, parking lots, driveways) are most recycled products with over $80 \%$ of the pavement removed each year being reused in various forms in the construction of new asphalt pavements. RAP is typically generated through milling a portion of the pavement structure or through full depth removal.

Waste materials have been reused instead of coarse or fine aggregates in concrete or mortars. ${ }^{1}$ Generally, scientists have been studied on improvement of toughness and workability of concrete and mortars. ${ }^{2}$ They proved that the replacement of waste materials as coarse or fine aggregates in concrete greatly improves the workability, toughness and energy absorbing capability. ${ }^{3}$ However, compressive and tensile strengths have been decreased. ${ }^{4,5}$ Asphalt forms a thin film at the interface of cement mortar and aggregate, which can be used to arrest crack propagation in concrete. $^{6}$ The results obtained with cement-treated materials and roller compacted concrete show that introduction of RAP in hydraulic materials leads to a decrease of splitting tensile strength

\footnotetext{
${ }^{1)}$ Eskipehir Osmangazi Univ., Dept. of Civil Engineering, 26480, Eskipehir, Turkey.

${ }^{2)}$ Anadolu University, Porsuk Vocational School, 26470, Eskipehir, Turkey. E-mail: bisikdag@anadolu.edu.tr.

Copyright (c) 2009, Korea Concrete Institute. All rights reserved, including the making of copies without the written permission of the copyright proprietors.
}

but also to a greater decrease of elastic modulus. Evolution of both properties lost interest in pavement material owing to the lower elastic modulus limits and the increase in pavement thickness due to the lower tensile strength.

The studies have presented various results obtained with concrete mixtures incorporating different amounts of RAP, and the permeability of blended RAP is similar to that of conventional granular material. ${ }^{7}$ Cement based materials are brittle and sensitive to cracking due to their poor capacity for deformation and low tensile strength. ${ }^{8}$ In this case, shrinkage can be improved with recycling of waste materials such as rubber of waste tires or reclaimed asphalt pavements etc. Several test methods have been used to determine free and restrained shrinkage behaviors of cement based materials. Restrained ring test has been the most popular among quality control tests for assessing the shrinkage cracking potential of cement based mixtures.

\section{Experimental study}

\subsection{Materials}

In experiments, CEM II/B-M 32.5 R Portland cement, city network water and CEN standard sand were used in respect of TS EN 197-1, TS 1247 and TS EN 196-1, respectively. The properties of cement and chemical analysis of mixture water is given in Tables (Table 1 and Table 2). The water/cement ratio was 0.5 in mortar series. The RAP was crushed into $0-4 \mathrm{~mm}$ to replace with standard sand. The unit weight of the RAP varies between 1,940 and $2,300 \mathrm{~kg} / \mathrm{m}^{3}$. However, the saturated specific weight and water absorption value of RAP were $2,530 \mathrm{~kg} / \mathrm{m}^{2}$ and $0.7 \%$ $0.8 \%$, respectively (Table 3 ).

\subsection{Experimental method}

In experiments, physical and mechanical properties of RAPM 
Table 1 Properties of CEM II/B-M 32.5 R Portland cement.

\begin{tabular}{c|c|c|c}
\hline \multicolumn{2}{c|}{ Chemical compositions (\%) } & \multicolumn{2}{|c}{ Physical properties } \\
\hline \hline $\mathrm{SiO}_{2}$ & 31.53 & Specific gravity & 2.85 \\
\hline $\mathrm{Al}_{2} \mathrm{O}_{3}$ & 7.06 & Specific surface $\left(\mathrm{cm}^{2} / \mathrm{g}\right)$ & 3574 \\
\hline $\mathrm{Fe}_{2} \mathrm{O}_{3}$ & 3.29 & & \\
\hline $\mathrm{CaO}$ & 48.89 & Compressive strengths $(\mathrm{MPa})$ \\
\hline $\mathrm{MgO}$ & 1.46 & $2^{\text {nd }}$ day & 12.8 \\
\hline $\mathrm{SO}_{3}$ & 2.01 & $7^{\text {th }}$ day & 26.9 \\
\hline $\mathrm{Cl}^{-}$ & 0.27 & $28^{\text {th }}$ day & 42.5 \\
\hline $\mathrm{LOI}$ & 4.55 & \multicolumn{2}{|}{} \\
\hline
\end{tabular}

Table 2 Properties of mixture water.

\begin{tabular}{c|c}
\hline Parameters & Values \\
\hline \hline $\mathrm{pH}$ & 6.85 \\
\hline Calcium $(\mathrm{Ca})^{++}$ & $58 \mathrm{mg} / \mathrm{l}$ \\
\hline Magnesium $(\mathrm{Mg})^{++}$ & $83 \mathrm{mg} / \mathrm{l}$ \\
\hline Chloride $(\mathrm{Cl})^{-}$ & $46 \mathrm{mg} / \mathrm{l}$ \\
\hline Sulfate $\left(\mathrm{SO}_{4}\right)^{--}$ & $45 \mathrm{mg} / \mathrm{l}$ \\
\hline Vaporization & $434 \mathrm{mg} / \mathrm{l}$ \\
\hline
\end{tabular}

Table 3 Physical and mechanical properties of RAP.

\begin{tabular}{c|c|c}
\hline $\begin{array}{c}\text { Type of } \\
\text { property }\end{array}$ & RAP property & Typical range of values \\
\hline \hline & Unit weight & $1,940 \sim 2,300 \mathrm{~kg} / \mathrm{m}^{3}$ \\
\cline { 2 - 3 } & Moisture content & $\begin{array}{c}\text { Normal: up to } 5 \% \\
\text { Maximum: } 7 \sim 8 \%\end{array}$ \\
\cline { 2 - 3 } $\begin{array}{c}\text { Physical } \\
\text { properties }\end{array}$ & Asphalt content & $\begin{array}{c}\text { Normal:4.5 6\% } \\
\text { Maximum range: } 3 \sim 7 \%\end{array}$ \\
\cline { 2 - 3 } & Asphalt penetration & Normal: $10 \sim 80$ at $25^{\circ} \mathrm{C}$ \\
\cline { 2 - 3 } & Absolute viscosity or & $\begin{array}{c}\text { Normal: } 4,000 \sim 25,000 \\
\text { poises at } 60^{\circ} \mathrm{C}\end{array}$ \\
\hline \multirow{3}{*}{$\begin{array}{c}\text { Mechanical } \\
\text { properties }\end{array}$} & Compacted unit weight & $1,600 \sim 2,000 \mathrm{~kg} / \mathrm{m}^{3}$ \\
\cline { 2 - 3 } & California bearing ratio & $\begin{array}{c}100 \% \text { RAP: } 20 \sim 25 \% \\
40 \% \text { RAP and } 60 \% \text { natural } \\
\text { aggregate: } 150 \%\end{array}$ \\
\hline
\end{tabular}

were investigated in addition to fractural behavior of ring specimens. The destructive and nondestructive tests were conducted on fresh and hardened mortars. The mixture ratios were determined due to the weight batch method. Mortars were produced with $450 \mathrm{~g}$ CEM II/B-M 32.5 R Portland cement per $1350 \mathrm{~g}$ CEN standard sand or RAP owing to replacement ratios. The water/cement ratio was kept constant at the ratio of 0.5 in all experiments. The volumetric mixture proportions and weight batch ratios of RAPM are shown in tables (Table 4 and Table 5). The RAP was used instead of sand with the replacement ratios of $0,25,50,75$ and $100 \%$ to produce specimens at dimensions of $40 \times 40 \times 160$, $25 \times 25 \times 285$ and $150 \times 150 \times 150 \mathrm{~mm}$, furthermore ring speci-
Table 5 Mixture proportions for $1 \mathrm{~m}^{3}$ RAPM.

\begin{tabular}{c|c|c|c|c}
\hline RAP $(\%)$ & Sand $(\mathrm{kg})$ & Cement $(\mathrm{kg})$ & Water $(\mathrm{kg})$ & RAP $(\mathrm{kg})$ \\
\hline \hline 0 & 1,760 & 580 & 290 & 0 \\
\hline 25 & 1,320 & 580 & 290 & 440 \\
\hline 50 & 880 & 580 & 290 & 880 \\
\hline 75 & 440 & 580 & 290 & 1,320 \\
\hline 100 & 0 & 580 & 290 & 1,760 \\
\hline
\end{tabular}

mens with $35 \mathrm{~mm}$ thick and $140 \mathrm{~mm}$ height were produced. The ring and $25 \times 25 \times 285 \mathrm{~mm}$ prismatic specimens were initially exposed to $20^{\circ} \mathrm{C}$ temperatures and $100 \%$ relative humidity (RH) during 24 hours. Afterward, specimens were exposed to temperature of $20^{\circ} \mathrm{C}$ and $50 \% \mathrm{RH}$ for 60 days while $70 \times 70 \times 70$, $40 \times 40 \times 160$ and $150 \times 150 \times 150 \mathrm{~mm}$ specimens were cured at $20^{\circ} \mathrm{C}$ in lime saturated water for 7 and 28 days to conduct mechanical tests (ASTM C 157).

In ring tests, outer mould of ring was removed 24 hour after casting, and silicone was used to prevent drying from the upper surface of mortar ring. The crack formations were observed during 60 days, and crack widths and lengths were measured each day. The average crack openings at the top, middle and bottom of ring mortar was considered for measuring crack widths. The mechanical and physical properties of $40 \times 40 \times 160$ and $150 \times$ $150 \times 150 \mathrm{~mm}$ specimens were tested at the end of the $7^{\text {th }}$ and $28^{\text {th }}$ days. The unit weight, ultrasound pulse velocity, compressive and flexural strengths were determined (ASTM C 349-02). Furthermore, elasticity modulus and abrasions were obtained on $150 \times$ $150 \times 150$ and $70 \times 70 \times 70 \mathrm{~mm}$ prismatic specimens, respectively (ASTM C 469-02).

\section{Results and discussion}

\subsection{Unit weight}

The hardened unit weight of RAPM decreased with the increase

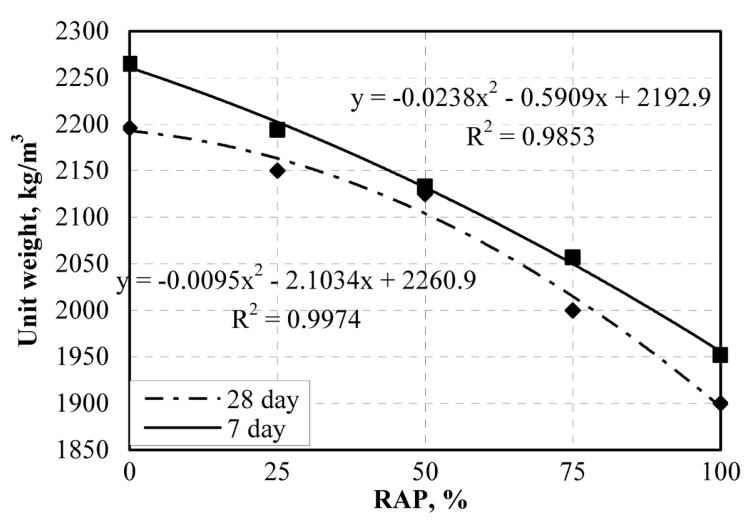

Fig. 1 Hardened unit weight of RAPM.

Table 4 Volumetric mixture proportions of RAPM.

\begin{tabular}{l|c|c|c|c}
\hline Experimental test & Specimen number & Dimension $(\mathrm{mm})$ & Volume $\left(\mathrm{m}^{3}\right)$ & \multicolumn{2}{|c}{ Total volume $\left(\mathrm{m}^{3}\right)$} \\
\hline Compressive strength & 6 & $40 \times 40 \times 40$ & \multicolumn{2}{|c}{ Obtained from flexural strength test } \\
\hline Flexural strength & 6 & $40 \times 40 \times 160$ & 0.0002560 & 0.0015360 \\
\hline Modulus of elasticity & 6 & $150 \times 150 \times 150$ & 0.0033750 & 0.0202500 \\
\hline Free shrinkage & 2 & $25 \times 25 \times 285$ & 0.0001782 & 0.0003563 \\
\hline Restrained shrinkage & 2 & Ring & 0.0043872 & 0.0087745 \\
\hline
\end{tabular}


in RAP ratio for both 7 and 28-day specimens (Fig. 1). The unit weights of RAPM were generally lower than the control series. This behavior occurs owing to the lower unit weight of RAP compared to natural sand. However, it was observed that the decrease rate in 7-day unit weight was similar with the decrease rate in 28day unit weight. However $13 \%$ decrease in unit weight with the $100 \%$ RAP content was observed for both 7 and 28-day specimens.

\subsection{Ultrasound pulse velocity}

The ultrasound pulse velocity was determined on $40 \times 40 \times$ $160 \mathrm{~mm}$ specimens. Approximately, 23\% and 20\% decrease in ultrasound pulse velocity were observed for 7 and 28-day specimens with the RAP content of $100 \%$, respectively (Fig. 2). The decrease in ultrasound pulse velocity can be explained by the porous structure of RAP.

\subsection{Compressive strength}

The decreases owing to porosity and lower strength of RAP in compressive strengths were observed with the increment in RAP content (Fig. 3). The best fit curve of compressive strength was approximately linear in 7-day specimens. The decreasing slope in 28-day specimens were higher for $25 \%$ RAP content, however the rest of the RAP content were linear likewise in 7-day specimens. The decrements in compressive strengths of 7 and 28-day RAPM specimens with the $100 \%$ RAP content were approximately $60 \%$. However RAPM with the RAP content between $25 \%$ and $75 \%$ were still adequate for various types of structures.

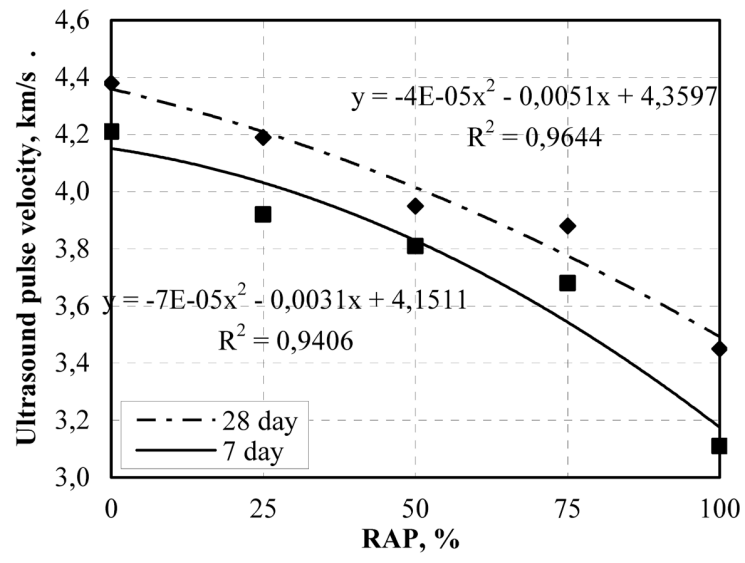

Fig. 2 Ultrasound pulse velocity of RAPM.

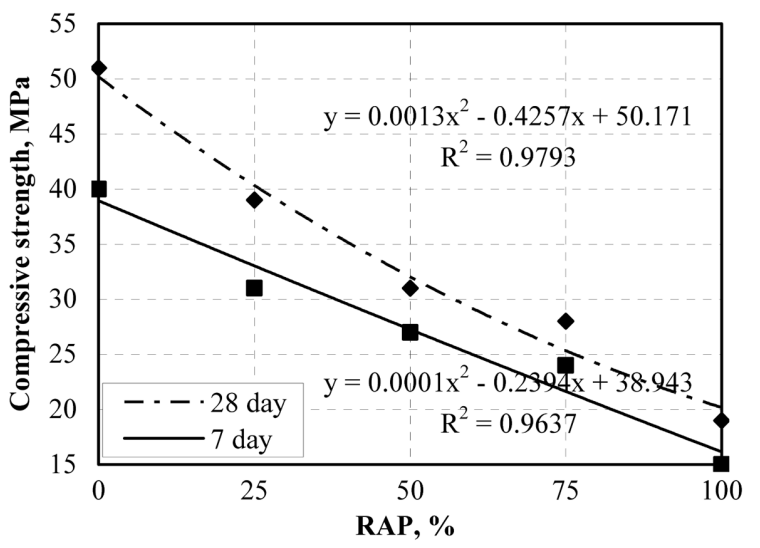

Fig. 3 Compressive strength of RAPM.

\subsection{Flexural strength}

The decrements in flexural strength were observed with the increasing RAP content (Fig. 4). Approximately, 40\% decrements in flexural strengths were observed in both 7 and 28-day specimens with the RAP content of $100 \%$, however lower replacement ratios $(25 \sim 75 \%)$ were acceptable due to the results. A linear decrement for both 7 and 28-day RAPM were obtained in experiments.

\subsection{Restrained shrinkage cracks}

The aim of the ring tests was to observe and determine restrained shrinkage cracks, initial cracking time, crack length and widths. Dimensions of the ring specimens, ring test set up and restrained shrinkage cracks are shown in figures (Figs. 5 to 7). In experiments, crack widths were measured with optical binoculars. It was observed that the initial time for restrained shrinkage cracking was delayed with the increment in RAP content (Table 6). Crack

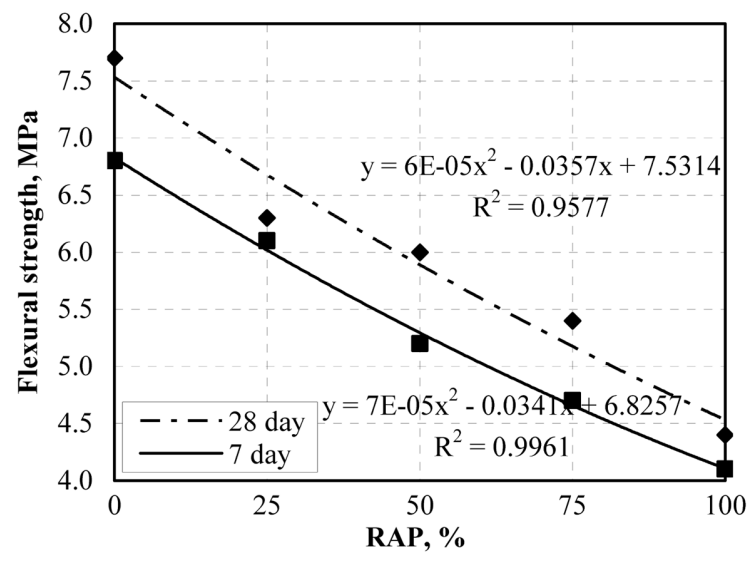

Fig. 4 Flexural strength of RAPM.

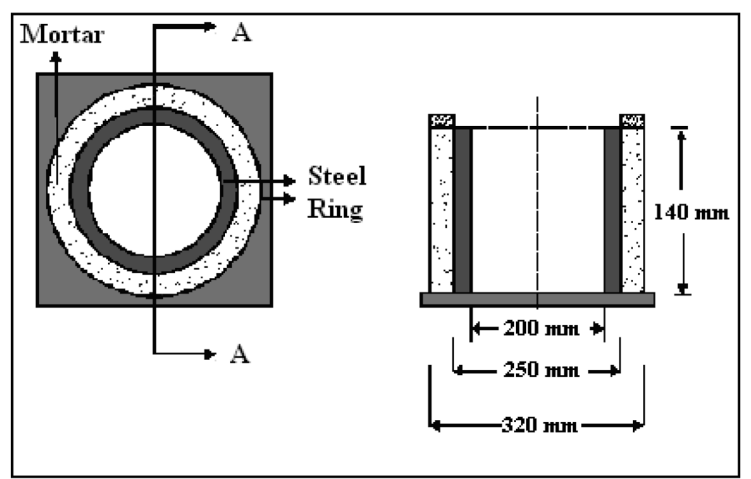

Fig. 5 Dimensions of a ring specimen.
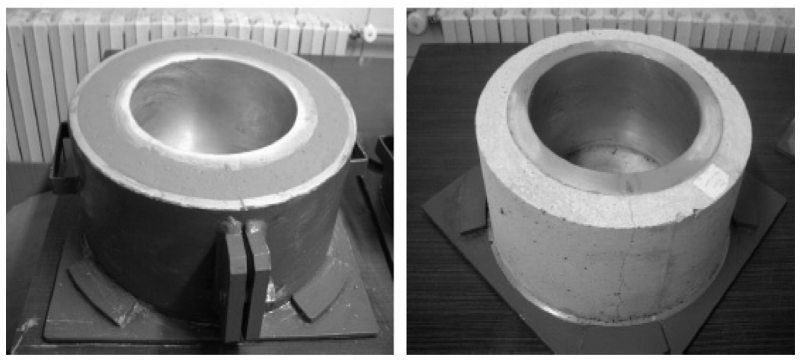

Fig. 6 Ring test set up. 

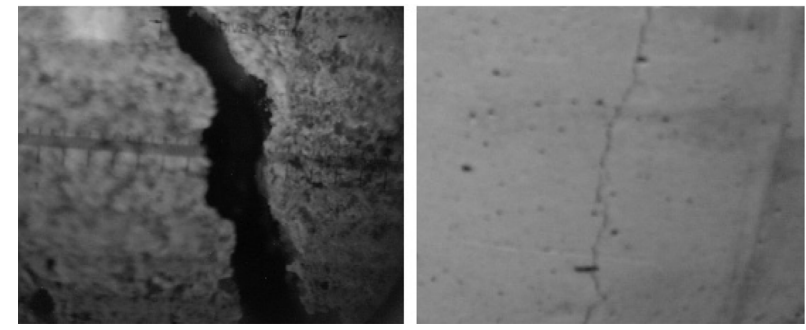

Fig. 7 Restrained shrinkage crack of RAPM $50 \%$ series.

Table 6 Restrained ring test results.

\begin{tabular}{l|c|c|c|c|c}
\hline \multicolumn{1}{c|}{ RAP (\%) } & 0 & 25 & 50 & 75 & 100 \\
\hline \hline First cracking time (day) & 17 & 21 & 23 & 26 & 27 \\
\hline Crack number for 60 days & 1 & 1 & 1 & 1 & 1 \\
\hline Main crack length for 60 days (mm) & 140 & 140 & 140 & 140 & 140 \\
\hline Max. crack opening (mm) & 0.70 & 0.47 & 0.39 & 0.32 & 0.17 \\
\hline
\end{tabular}

widths were decreased and first cracking was also delayed systematically with the increment in RAP content. Approximately, 75\% decrement in crack width of RAPM 100\% series was observed compared to control series (Fig. 8). The highest first cracking time and lowest crack width were both observed in series of RAPM $100 \%$. This is explained by the porous structure of RAPM (Fig. 9). This leads lower strength development and modulus of elasticity for the higher RAP content. As is known, lower compressive strength and modulus of elasticity leads a delay in crack formation and also leads lower crack width formation. The porosity is the most effective reason on delayed crack formation. However, in this study, it was proved that lower replacement ratios (25 50\%)

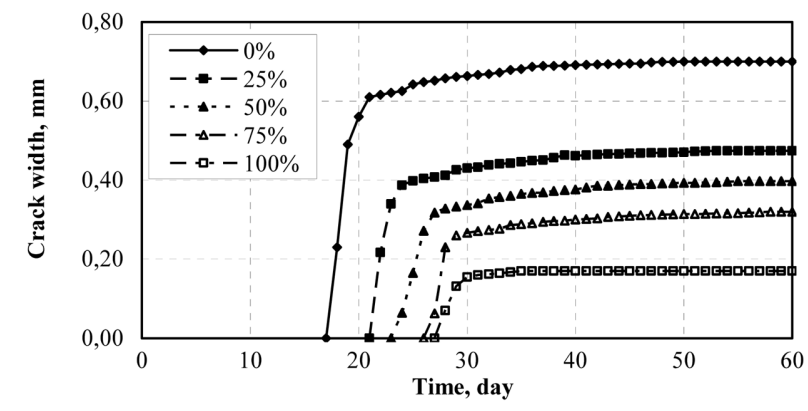

Fig. 8 Crack width of restrained shrinkage for RAPM.

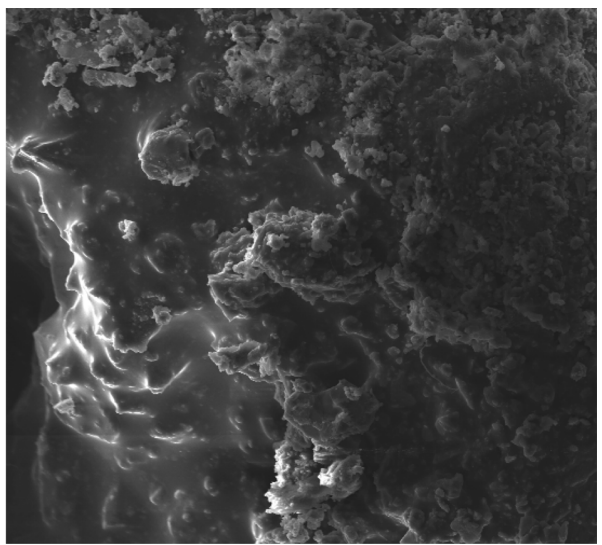

Fig. 9 Microstructure of RAPM (EHT:20.00 kV, WD: $9 \mathrm{~mm}$, Mag: 591x). of RAP were adequate for obtaining delayed crack formation due to the modulus of elasticity results and compressive strengths. The RAP contents of $50 \sim 100 \%$ were excessively high in experiments to obtain appropriate elasticity modulus, however the RAP ratios of $0-10-20-30-40-50 \%$ which have lower intervals will be preferred. Nevertheless, crack widths in all series were still lower than the crack widths of control series. This was verified with the behavior of modulus of elasticity.

The initial cracks occurred in $17^{\text {th }}, 21^{\text {st }}, 23^{\text {rd }}, 26^{\text {th }}$ and $27^{\text {th }}$ days for the $0,25,50,75$ and 100\% RAP content, respectively; after exposure of $20^{\circ} \mathrm{C}$ and relative humidity of $50 \%$. The crack widths approximately reached to final width after 40 days for all series. However, the crack formations were faster in first 4 days after first crack. It was observed that the slope of the curves for all series were similar. In other words, first cracking delayed and final crack formation was slowed down with the increment in RAP content. However due to the results, this situation is more effective for the series of $50 \sim 100 \%$ owing to excessively porous structure compared to other series. Thus minimum crack widths were obtained in $100 \%$ RAP content. The maximum and minimum crack widths were obtained as 0.70 and $0.17 \mathrm{~mm}$ for control and $100 \%$ series respectively, after 60 days of exposure time. Similarly, crack lengths were also delayed with the increment in RAP content. The crack lengths reached to final length $(140 \mathrm{~mm})$ generally for 10 days in all series and remained constant. The measurements of crack width were all conducted on main cracks; no sub-cracks were occurred on specimens during 60 day period.

\subsection{Free shrinkages}

In experiment, similar curing conditions were applied with the restrained shrinkage test $\left(20^{\circ} \mathrm{C}\right.$ and $\left.50 \% \mathrm{RH}\right)$. Higher RAP content leads lower unit deformation due to lower water absorption capacity however; it was observed that the unit deformations in free shrinkage tests of RAPM specimens systematically increased with the increase in RAP content. Approximately 40\% increment was obtained in $100 \%$ RAPM series compared to the control series. This is explained as the lower modulus of elasticity ensures less restraint in cement paste for free shrinkage. The less stiff aggregate reduces the internal strain and thus increase the elongation in free shrinkage test. Control series and $25 \%$ series were similar compared to other series (Fig. 10).

\subsection{Modulus of elasticity}

In experiments, modulus of elasticity was obtained with the

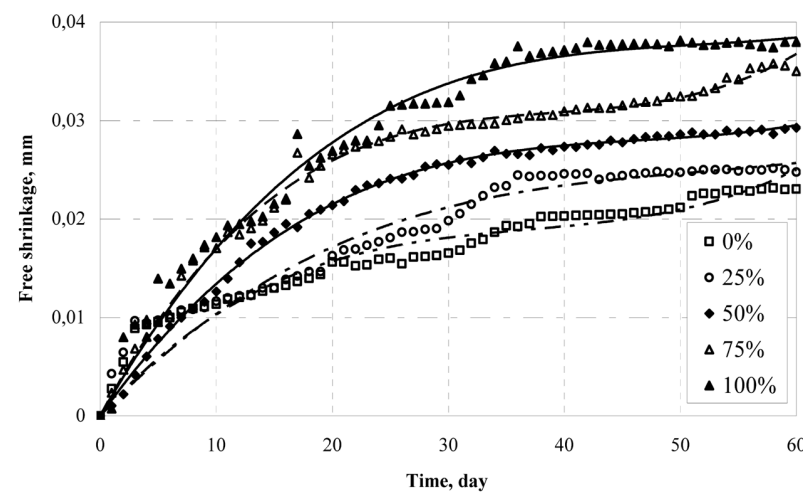

Fig. 10 Unit deformations of free shrinkage for RAPM. 
tests conducted on 28-day RAPM specimens (Fig. 11). Modulus of elasticity decreased systematically with the increment in RAP content. The variations are approximately linear up to ratio of $50 \%$ RAP and polynomial after series of $50 \%$. It was observed that the deformation values for $75 \sim 100 \%$ series were similar. However, the experimental moduli of elasticity of each specimen were higher in series of control and 25\% RAP compared to other series. The lowest value was obtained in series of $100 \%$; approximately $65 \%$ decrement was obtained in this series compared to control series. Internal restraint decreased with the decrease in compressive strength and modulus of elasticity.

\subsection{Abrasion}

The abrasion tests were conducted on $70 \times 70 \times 70 \mathrm{~mm}$ RAPM specimens by Bohme disc (TS 699). It was observed that the abrasion increased with the increase in RAP ratio (Fig. 12). The minimum and maximum abrasions were obtained as 7.0 and $8.6 \mathrm{~cm}^{3} /$ $50 \mathrm{~cm}^{2}$ on 25 and $100 \%$ RAPM series, except control series. It was proved that the lower replacement ratios of RAP can be appropriate for several constructions.

\section{Conclusions}

The optimum RAP content for mechanical properties was obtained between $25 \%$ and $50 \%$ series. The restrained shrinkage test results of RAPM were adequate at higher RAP content despite the lower strengths. However, free shrinkage behavior was totally

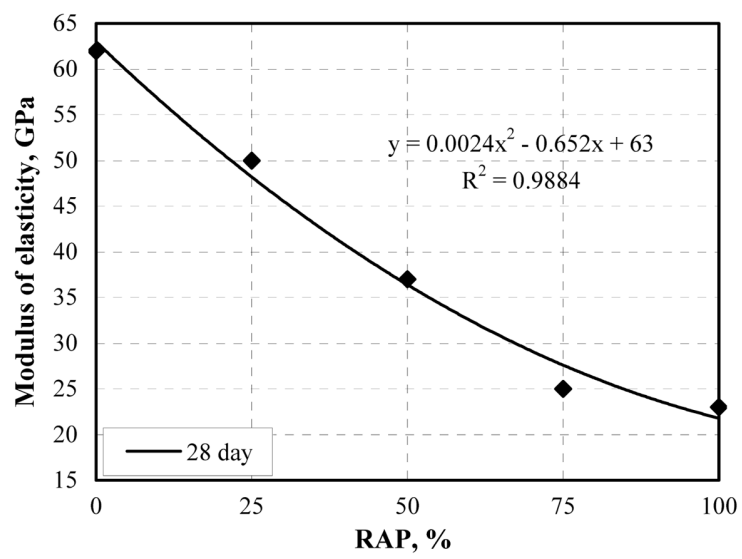

Fig. 11 Experimental modulus of elasticity for RAPM.

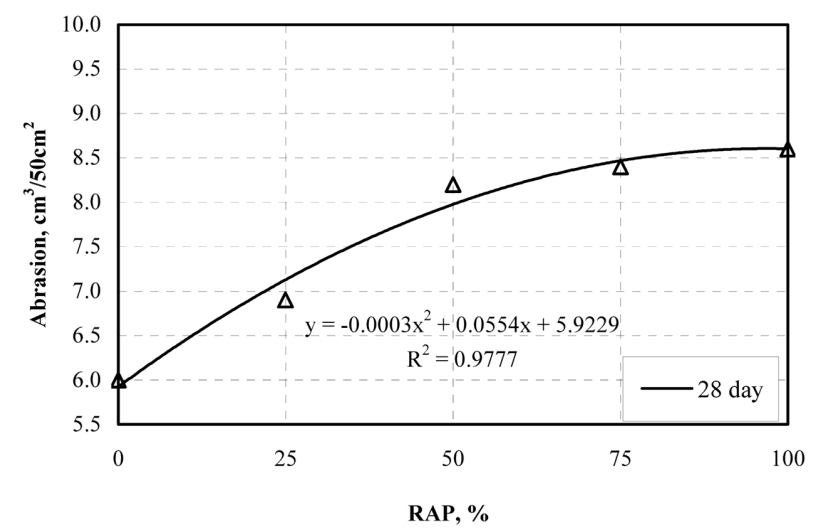

Fig. 12 Abrasion values for RAPM. opposite of restrained shrinkage which is explained with the "lower modulus of elasticity ensures less restraint in cement paste for free shrinkage." The crack widths are in acceptable ranges for all series due to restrained shrinkage test results. In fact, crack widths were reduced with the increase in RAP content. Nonetheless, the crack formations and first cracking were delayed. The acceleration for crack width formation was eligible for all series. In general, experimental results barely obtained with high replacement ratios of waste materials as aggregate in concrete or mortars, consequently lower ratios (up to $30 \sim 40 \%$ ) are preferred in studies. However, in this study, results were obtained with both high and low replacement ratios despite remarkable decrements in strengths. The results show that incorporation of RAP modified mortars is adequate for delaying crack formation and reducing crack opening. The RAP enhances the strain capacity of mortars despite the decrease in mechanical properties. Shrinkage is the most effective reason for cracking in cement based materials. It is expected that the aggregate which is less stiff decreases the internal restraint.

\section{References}

1. Nagataki, S., Gökçe, A., Saeki, T., and Hisada, M., "Assessment of Recycling Process Induced Damage Sensitivity of Recycled Concrete Aggregates," Cement and Concrete Research, Vol. 34, No. 6, 2004, pp. 965 971.

2. Malhotra, V. M., Zhang, M. H., Read P. H., and Ryell, J., "Long-term Mechanical Properties and Durability Characteristics of High-strength/high-performance Concrete Incorporating Supplementary Cementing Materials under Outdoor Exposure Conditions," Journal of ACI Materials, Vol. 97, No. 5, 2000, pp. 518 525.

3. Huang, B., Shu, X., and Li, G., "Laboratory Investigation of Portland Cement Concrete Containing Recycled Asphalt Pavements," Cement and Concrete Research, Vol. 35, No. 10, 2005, pp. 2008 2013.

4. Li, G, Stubblefield, M. A., Garrick, G, Eggers, J., Abadie, C., and Huang, B., "Development of Waste Tire Modified Concrete," Cement and Concrete Research, Vol. 34, No.12, 2004, pp. 2283 2289.

5. Topçu, Ý. B., "The properties of Rubberized Concrete," Cement and Concrete Research, Vol. 25, No. 2, 1995, pp. 304 310.

6. Huang, B., Li, G., Pang, S. S., and Eggers, J., "Investigation into Waste Tire Rubber-filled Concrete," Journal of Materials in Civil Engineering, Vol. 16, No. 3, 2004, pp. 187 194.

7. Decker, D. S. and Young, T. J., "Handling RAP in an HMA Facility," Proceedings of the Canadian Technical Asphalt Association, Edmonton, Alberta, Canada, 1996, pp. 23 30.

8. Turatsinze, A., Bonnet, S., and Granju, J. L., "Potential of Rubber Aggregates to Modify Properties of Cement Based Mortars: Improvement in Cracking Shrinkage Resistance," Construction and Building Materials, Vol. 21, No. 1, 2007, pp. 176 181.

9. Hossain, A. B. and Weiss, J., "The Role of Specimen Geometry and Boundary Conditions on Stress Development and Cracking in the Restrained Ring Test," Cement and Concrete Research, Vol. 36, No. 1, 2006, pp. 189 199. 